\title{
Isolation and Characterization of Multipotent Stem Cells from The Olfactory Mucosa and Olfactory Bulb of The Adult Male Albino Rats

\author{
MOHAMMED ABDEL-RAHMAN ${ }^{1}$, RANIA A. GALHOM ${ }^{2}$, WAEL AMIN \\ NASR EL-DIN ${ }^{2,4}$, MONA H. MOHAMMED ALI ${ }^{2}$, ALAA EL-DIN SAAD \\ ABDEL-HAMID ${ }^{3}$
}

${ }^{1}$ Department of Anatomy \& Embryology, Faculty of Medicine, Sohag University, Sohag, Egypt, ${ }^{2}$ Department of Anatomy \& Embryology, Faculty of Medicine, Suez Canal University, Ismailia, Egypt, ${ }^{3}$ Department of Clinical Pathology, Faculty of Medicine Suez Canal University, Ismailia, Egypt, ${ }^{4}$ Department of Anatomy, Ibn Sina National College for Medical Studies, Jeddah, Saudi Arabia.

\begin{abstract}
Olfactory stem cells (OSCs) are multipotent stem cells that can be isolated from the olfactory mucosa and olfactory bulb and have the capacity to proliferate when cultured on suitable media. Isolation of these cells helps to study their identity before being used as a cell therapy.

The aim of this study is to isolate rat OSCs from olfactory mucosa and olfactory bulb, culture these OSCs in suitable medium to allow for their proliferation.

Results: OSCs were successfully isolated, cultured and expanded in Dulbecco's Modified Eagle's Medium with Ham's F12 (DMEM F-12) media supplemented with $10 \%$ fetal bovine serum (FBS). The cells were characterized morphologically by their spindle shape cytoplasmic processes, plastic adherence tendency and colony formation till the 3rd passage. They were characterized immunohistochemically by their positive expression for CD44 and Nestin and negative expression for CD34.

Key words: Culture, characterization, isolation, morphology, olfactory stem cells, phenotype.
\end{abstract}

\section{Introduction}

The olfactory mucosa is located in the nasal cavity and contains a large population of stem cells that undergo division, neurogenesis and regeneration throughout life $(\mathbf{1}, \mathbf{2})$. The olfactory epithelium is the most superficial layer of the mucosa and it is the part of the nervous system that produces new neurons every day through neurogenesis that continues throughout the postnatal life to replace those that are damaged by pollution, bacterial or viral infections $(\mathbf{3}, \mathbf{4})$. The olfactory epithelial neural stem cells are present in the basal layer of the olfactory epithelium and they are the source of regeneration of this tissue after damage through the production of new sensory neurons that develop synapses to remake connections to the brain (5). The olfactory stem cells are also present within the layer of lamina propria that lies below the epithelium and these cells show both mesenchymal and neural characteristics of stem cells (6) but, the stem cells located in the lamina propria are closely related to bone marrow mesenchymal stem cells (BM-MSCs), so they are named olfactory ectomesenchymal stem cells (OE-MSCs) (7).

Multipotent stem cells derived from the olfactory mucosa can be cultured on various culture conditions to replicate and generate neurospheres that are multipotent that can give rise to neurons and glial cells, so, they are useful for transplantation therapies and for cellular studies of diseases (8) 
particularly, because the olfactory mucosa is easily accessible and can be obtained by a simple biopsy performed through the external nares (9).

Neural stem cells have been also isolated and characterized from the olfactory bulb (10). Due to their ability to self-renew and to differentiate towards the neuronal phenotype, the olfactory bulb neural stem cells (OBNSCs) provide an attractive tool for developing transplantation-based therapy of neurodegenerative diseases (11). The stem cells in the olfactory bulb are derived from the neural stem cells that lie in the walls of the lateral ventricles of the brain as they continue to differentiate after birth and give rise to neuroblasts through neurogenesis and the new cells migrate to the olfactory bulb throughout life (12) and the new neurons that reach the olfactory bulb become interconnected with the other neurons of the olfactory bulb by developing synapses and become included in the olfactory pathway (13). Also, the original cells of the olfactory bulb undergo neurogenesis that is well characterized in rodents and adult monkeys (14).

Olfactory mucosa derived stem cells are fusiform, fibroblast-like cells. During their initial colony forming unit like fibroblasts (CFU-F), they are negative for hematopoietic surface markers; CD 34,CD 45 and CD14 but positive for a variety of markers including Stro-1, CD 44, CD 29, CD 105, CD 73, CD 166 and CD 90 (15, 16). The stem cells isolated from the olfactory bulb are also fibroblast-like cells and express CD29, CD44, CD90, CD105 and CD166 but not CD34 and CD45, consistent with the characteristics of MSCs and are capable of differentiation into mesenchymal lineages such as osteocytes, chondrocytes and adipocytes (17). Study of these cell identities and their mesenchymal like characteristics is an issue of interest for their future use as a cyto therapy. So, the aim of our study was to develop an efficient and reproducible procedure to isolate OSCs fron rat olfactory mucosa and olfactory bulb and to introduce a culture system that allows the proliferation of these stem cells.

\section{Materials and methods}

Isolation of stem cells from the olfactory mucosa and olfactory bulbs:

- The olfactory stem cells were isolated from the rat olfactory mucosa and olfactory bulbs under very restricted sterile conditions. Ten adult male albino rats were used as a source of stem cells from the olfactory mucosa (18) and olfactory bulbs (19). Their age was 6 month and their weight ranged between 200 and 250 grams each.

\section{Culture of the olfactory stem cells:}

The final pellet was resuspended in $10 \mathrm{ml}$ complete medium that consists of low-glucose Dulbecco's Modified Eagle's Medium with Ham's F12 (DMEM-F12) supplemented with $10 \%$ fetal bovine serum and $1 \%$ penicillin/streptomycin (20 - 23).

Characterization of the olfactory stem cells:

Characterization of the olfactory mucosa derived cells will be performed using immunocytochemical markers specific for stem cells according to the criteria of the international society of cytotherapy (24). including Nestin (25), CD34 and CD44 markers (26):

* Olfactory stem cells growing in 35 $\mathrm{mm}$ dishes were fixed by chilled acetone: methanol $(1: 1)$ for 10 minutes and washed twice with PBS. Sections were treated with $0.3 \%$ hydrogen peroxide in methanol (30 $\mathrm{min})$ to abolish endogenous peroxidase. The cells were incubated for 30 minutes at room temperature with CD34, CD44, and nestin monoclonal antibodies (1:200 dilutions in PBS) then washed 
SOHAG MEDICAL JOURNAL

Vol. 21 No.3 october 2017 twice by PBS. The cells were incubated with peroxidases conjugated rabbit anti-mouse $\operatorname{IgG}$ secondary antibody for 30 minutes at $37^{\circ} \mathrm{C}$. Final wash three times with PBS was performed. A negative control was performed using only the secondary antibody to exclude any cross-reaction. The cells were examined with phase contrast microscope and CD34, CD 44, and nestin reaction was observed by the bright field.

\section{Results}

\section{Cultured olfactory stem cells:}

In primary culture after 3 days, OSCs adhered to the dish substratum, showing a small population of single cells. The cells gained small processes and became spindle shaped, with single nucleus (Fig. 1). The non-adherent cells were removed.

Five days after plating, the cells increased in number and their processes began to elongate (Fig. 2).

One week after plating, the population of cells was long, spindle shaped, with a fibroblast-like appearance, and began to form colonies (Fig. 3).

Ten days after plating, the number of cultured cell was markedly increased (Fig. 4).

At the end of the second week after plating, the cultured cells reached about $80 \%$ confluent and they took different morphological characters such as: spindle or star shaped. Some of them were polygonal or had a fibroblast-like appearance (Fig. 5).

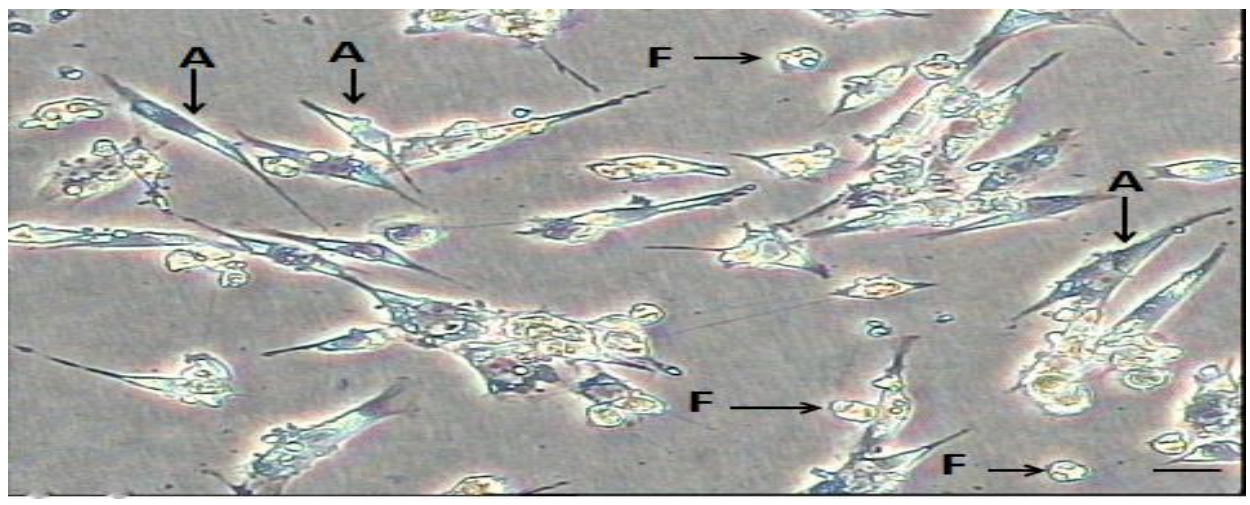

Figure 1: A phase contrast photomicrograph of primary cultured olfactory stem cells derived from rat olfactory mucosa and olfactory bulb 3 days after culture before wash. Some floating cells (F) are seen but large number of cells begins to attach (A) to the substratum and to gain processes. Scale bar $100 \mu \mathrm{m}$. X100.

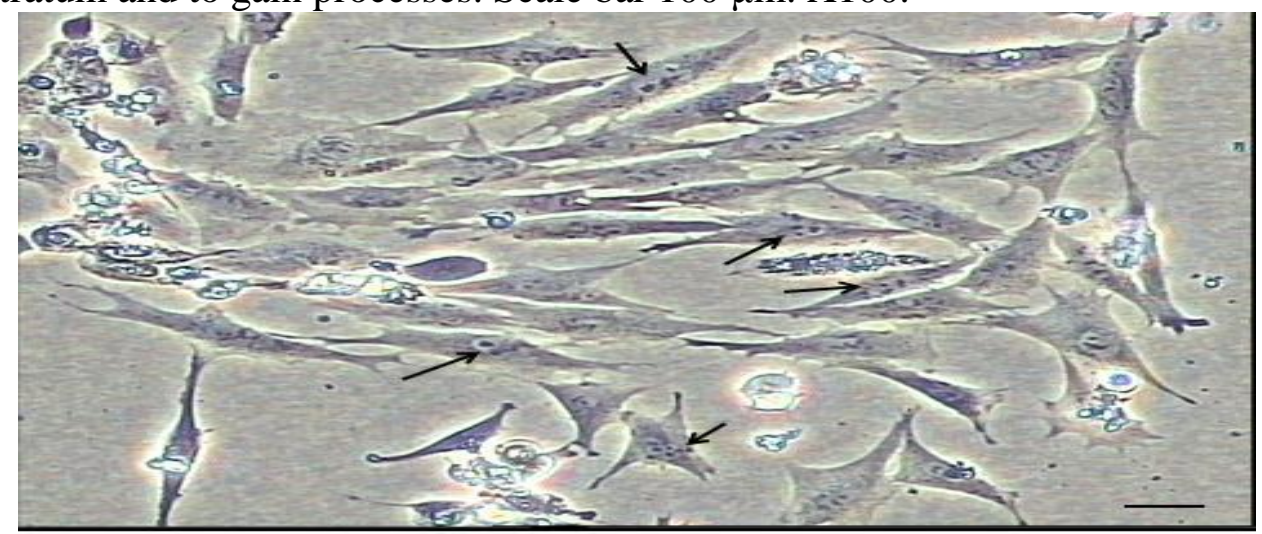

Figure 2: A phase contrast photomicrograph of primary cultured olfactory stem cells derived from rat olfactory mucosa and olfactory bulb 5 days after culture showing the 
SOHAG MEDICAL JOURNAL

Vol. 21 No.3 october 2017
Isolation and Characterization of Multipotent Stem Cells MOHAMMED ABDEL-RAHMAN

presence of some cells with their nuclei having multiple nucleoli (Arrows). Scale bar $100 \mu \mathrm{m}$. X100.

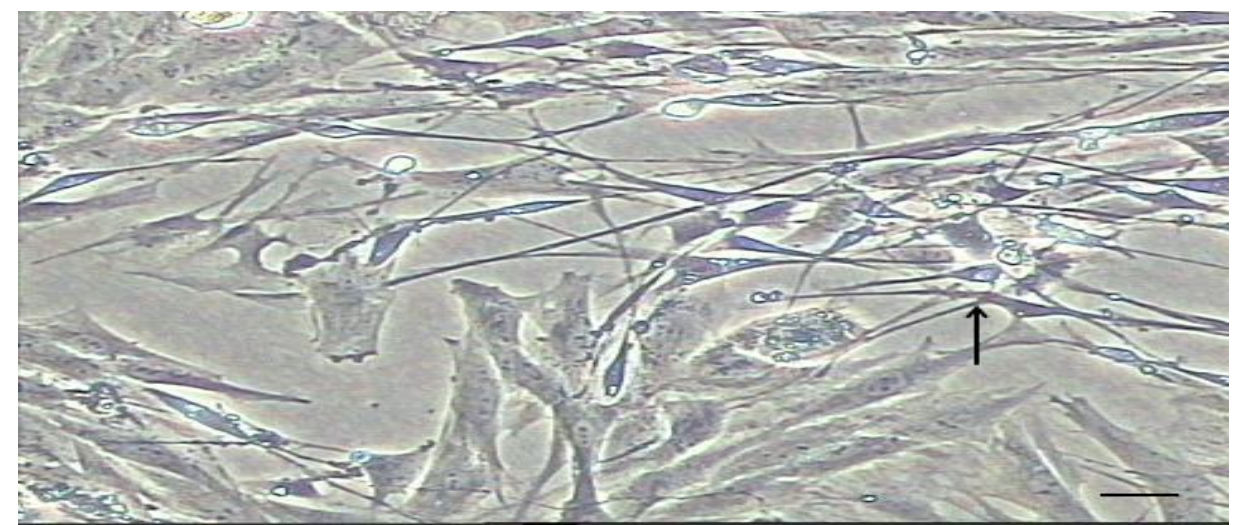

Figure 3: A phase contrast photomicrograph of primary cultured olfactory stem cells derived from rat olfactory mucosa and olfactory bulb one week after culture showing the presence of a cell colony (Arrow) and more than 50\% conflouency. Scale bar 100 $\mu \mathrm{m}$. X100.

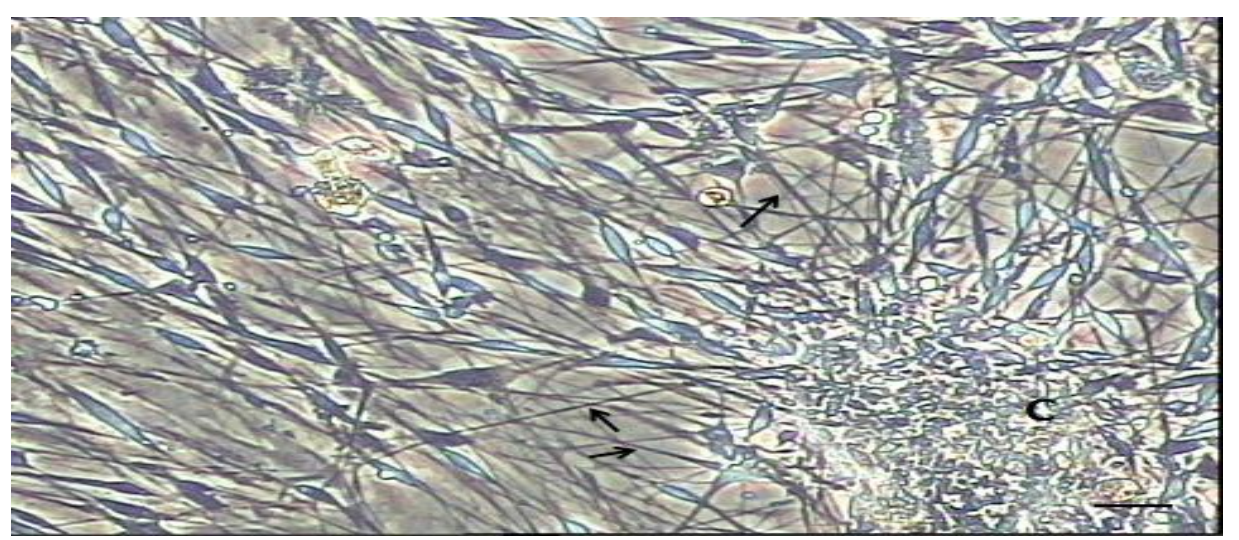

Figure 4: A phase contrast photomicrograph of primary cultured olfactory stem cells derived from rat olfactory mucosa and olfactory bulb 10 days after culture. The cells show $90 \%$ confluency with marked elongation of their processes (Arrows) with the presence of a cell colony (C). Scale bar $100 \mu \mathrm{m}$. X100.

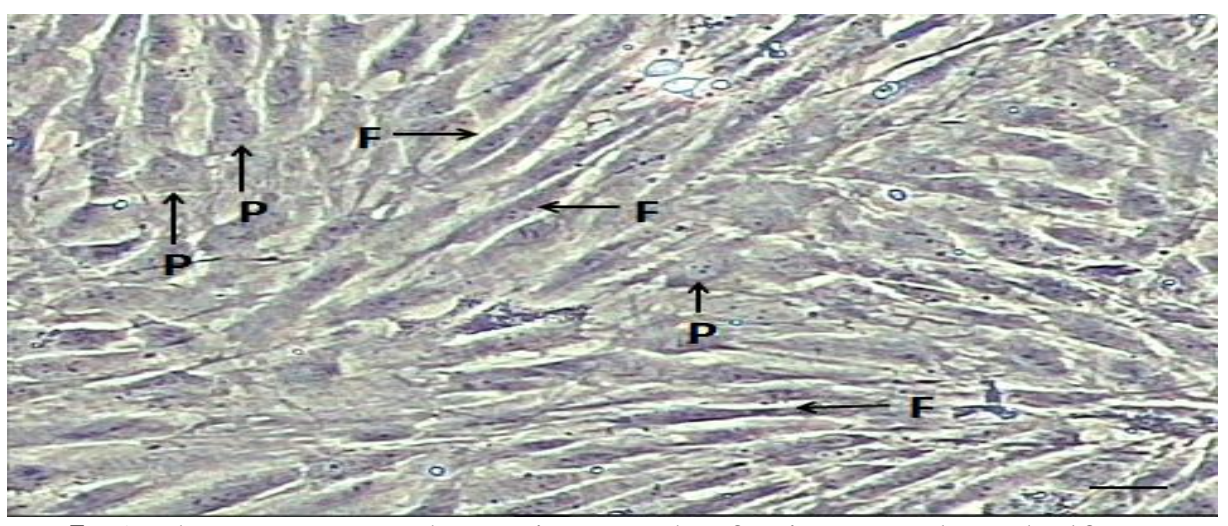

Figure 5: A phase contrast photomicrograph of primary cultured olfactory stem cells derived from rat olfactory mucosa and olfactory bulb 2 week after culture. The cells are confluent. Most of The cells are polygonal (P) and some are fibroblast-like (F). Scale bar $100 \mu \mathrm{m}$. X100. 


\section{Characterization of rat olfactory stem cells}

The identity of olfactory mucosa derived stem cells was proven by performing immunohistochemical staining using monoclonal antibodies against rat CD34, CD44, and Nestin. The performance of the immunohistochemical characterization was done on a monolayer of expanded rat olfactory stem cells of the third passage. These cells revealed that they were uniformly positive for CD44 (Fig. 6) and Nestin (Fig. 7) in the form of brown cytoplasmic staining. In contrast, they were negative for CD34 (Fig. 12).

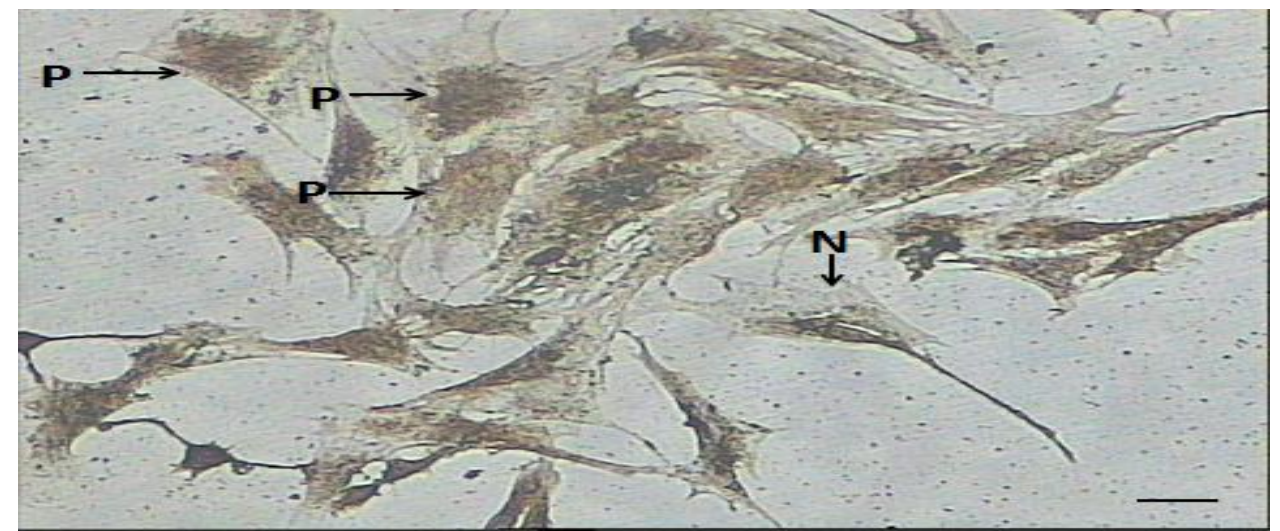

Figure 10: A phase contrast photomicrograph of immunostaining for surface antigen CD44 in a monolayer of rat olfactory stem cells during the third passage. Most of the cells are positively stained $(\mathrm{P})$ with few cells are negatively stained $(\mathrm{N})$. Scale bar 100 $\mu \mathrm{m}$. X100.

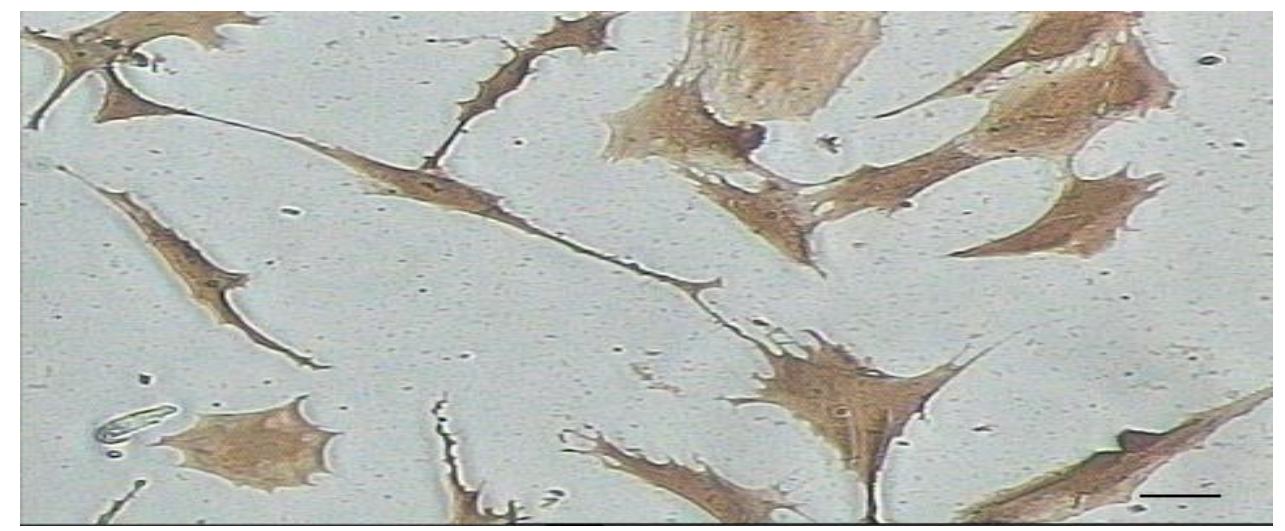

Figure 11: A phase contrast photomicrograph of immunostaining for surface antigen nestin in a monolayer of rat olfactory stem cells during the third passage. The cells (Arrows) are positively stained. Scale bar $100 \mu \mathrm{m}$. X 100.

\section{Discussion}

This paper presents a detailed protocol to isolate, culture and characterize olfactory mesenchymal stem cells from the olfactory mucosa and olfactory bulb of the adult male albino rats and this was in correlation with the results of the studies done by Kuijten et al., (2014) as they detected that, the rat nasal olfactory mucosa contains mesenchymal stem cells named olfactory mucosa derived mesenchymal stem cells(OM-MSCs) (27) and Gritti et al., (2002) who isolated the olfactory stem cells from the olfactory bulbs of rodents (28). Also, Curtis et al., (2007) detected that, human neuroblasts migrate from 
the wall of lateral ventricles to the olfactory bulb (29).

Olfactory stem cells have been previously described as a highly proliferative cell type (7) and this characteristic was confirmed in current research. Indeed, even though we established our cultures from very small pieces of tissue, several millions of cells were derived in less than a month time and we confirm here that rat olfactory stem cells can be successfully amplified by successive cell passages. We identified the olfactory stem cells through their characters by being positive for Nestin and CD44 and this was in correlation with those results found by JeanClaude et al., (2014) and Sayuri et al., (2010) who proved that the olfactory stem cells are positive for

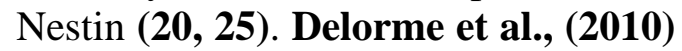
also detected that, the two recognized characteristics of the olfactory mucosa derived stem cells are the sphere formation and immuno-positivity for Nestin (7). Hosseini et al., (2015) proved that the olfactory stem cells are positive for CD44 (26).

In our study, we cultured the OSCs on DMEM-F12 enriched with fetal bovine serum with the addition of $1 \%$ Penicillin-Streptomycin because DMEM-F12 medium is stable, improves cell viability and growth, potentially increases the proliferation of stem cells and minimize toxic ammonia build-up according to previous studies that used DMEN-F12 to culture OSCs derived from olfactory mucosa $(30,31)$ and olfactory bulb (32) and other types of stem cells such as human embryonic stem cells (33), human-induced pluripotent stem cells (34), neural stem cells (35) and hairfollicle bulge stem cells (36). The culture medium was supplemented with fetal bovine serum (FBS) because it has a very low level of antibodies and contains more growth factors, allowing for proliferation in many different cell culture applications. Also, FBS is rich in a variety of proteins that maintain cultured cells in a medium in which they can survive, grow and divide so, it is the most widely used serumsupplement for the in vitro cell culture of eukaryotic cells $(37,38)$. The $1 \%$ Penicillin-Streptomycin was added to the culture medium to prevent bacterial growth (39). In addition, Ercolin et al., (2016) used DMEM F12 supplemented with $15 \%$ bovine fetal serum with $1 \%$ PenicillinStreptomycin to culture the olfactory stem cells obtained from the rabbit olfactory mucosa (40).

In the current study, most of the OSCs got attached to the plastic Petri dishes with polygonal and fibroblastlike morphology with small body and few long cytoplasmic processes with the formation of cell coloneis in the first culture and these were in correlation with the information given by the International Society for Cellular Therapy that has proposed that, the different types of mesenchymal stem cells including the OSCs show plastic adherent properties under normal culture conditions and has a fibroblast-like morphology (41). Also, Ercolin et al., (2016) detected that olfactory stem cells can be classified as MSCs due to their ability of adhesion to plastic culture dishes, fibroblastic morphology and formation of colonies with spindle morphology as fibroblasts during the first cultures (40). Moreover, these results are consistent in correlation with a previous results of s study done by Girard et al., (2011) who isolated olfactory stem cells from the rat and human olfactory mucosa and when cultured revealed polygonal and fibroblast-like morphology with few long processes and small cell body (42). 


\section{References}

1- Feron F, Perry C, Girard SD and Mackay-Sim A. (2013): Isolation of adult stem cells from the human olfactory mucosa. Methods Mol Biol, 1059:107-114.

2- Barnett SC and Riddell JS (2004): Olfactory ensheathing cells (OECs) and the treatment of CNS injury: advantages and possible caveats. $\mathbf{J}$

Anat; 204 (1):57-67

3- Graziadei GA. (1979): Neurogenesis and neuron regeneration in the olfactory system of mammals. II. Degeneration and reconstitution of the olfactory sensory neurons after axotomy. J Neurocytol; 8:197-213.

4- Roisen FJ. (2001): Adult human olfactory stem cells. Brain Res; 890:11-22.

5- Leung CT, Coulombe PA and Reed RR. (2007): Contribution of olfactory neural stem cells to tissue maintenance and regeneration. Nature Neurosci; 10(6):720-726.

6- Tome M, Lindsay SL, Riddell JS and Barnett SC. (2009): Identification of nonepithelial multipotent cells in the embryonic olfactory mucosa. Stem Cells; 27:2196-2208.

7- Delorme B, Nivet E, Gaillard J, Haupl T, Ringe J, Deveze A, Magnan J, SohierJ, Khrestchatisky $M$ and Roman FS. (2010): The human nose harbors a niche of olfactory ectomesenchymal stem cells and osteogenic properties. Stem Cells Dev; 19 (6):853-866.

8- Murrell W, Wetzig A, Feron F, Splatt K, Cameron N and Bellette B. (2005): Multipotent stem cells from adult olfactory mucosa. Dev Dyn; 233(2):496-515.

9- Feron F, Perry C, McGrath JJ and Mackay-Sim A. (1998): New techniques for biopsy and culture of human olfactory epithelial neurons. Arch Otolaryngol Head Neck Surg; 124:861-866.
10- Marei HE, Farag A, Althani A, Afifi N, Abd-Elmaksoud A, Lashen S and Cenciarelli C. (2015): Human olfactory bulb neural stem cells expressing hNGF restore cognitive deficit in Alzheimer's disease rat model. J cell Physiol; 230(1):116130.

11-Park KI, Teng YD and Snyder EY. (2002): The injured brain interacts reciprocally with neural stem cells supported on scaffolds to reconstitute lost tissue. Nat Biotechnol; 20:111-117.

12- Ming GL and Song H. (2011): Adult neurogenesis in the mammalian brain: significant answers and significant questions. Neuron; 70:687-702.

13- Lazarini F and Liedo PM. (2011): Is adult neurogenesis essential for olfaction? Trends Neurosci; 34:2030.

14- Kornack DR and Rakic P. (2001): The generation, migration, and differentiation of olfactory neurons in the adult primate brain. Proc Natl Acad Sci USA; 98:4752-4757.

15- Dominici M, Le Blanc K, Mueller I, Slaper-Cortenbach I, Marini F, Krause D, Deans R, Keating A, Prockop D and Horwitz E. (2006): Minimal criteria for defining multipotent mesenchymal stromal cells. Cytotherapy; 8(4):315-317.

16- Foster LJ, Zeemann PA, Li C, Mann M Jensen ON and Kassem M. (2005): Differential expression profiling of membrane proteins by quantitative proteomics in a human mesenchymal stem cell line undergoing osteoblast differentiation. Stem Cells; 23:1367-1377.

17- Huang YS, Li IH, Chueh SH, Hueng DY, Tai MC, Liang CM, Lien SB, Sytwuan HK and Ma KH. (2015): Mesenchymal stem cells from rat olfactory bulbs can differentiate into cells with 
cardiomyocyte characteristics. J of Tissue Eng and Regen Med; 9(12):191-201.

18- Girard S, Deveze A, Nivet E, Gepner B, Roman F and Feron F. (2011): Isolating nasal olfactory stem cells from rodents or humans. $\mathrm{J}$ Vis Exp; 54:2762.

19- Chen F, Qiu JH, Wang JL, Liu SL and Mi WJ (2004): Culture of neural stem cells from rat olfactory bulb. Journal of Zhonghua Er Bi Yan Hou Ke Za Zhi; 39:687-690.

20- Jean-Claude S, Stephane D, Antoine V, Gilles S, Michel K, Francois F and Francois S. (2014): A unique method for the isolation of nasal olfactory stem cells in living rats. Stem cell Res; 12:673-679.

21- Ohnishia YI, Iwatsukia K, Ishiharaa M, Shikinab T, Shinzawac $\mathrm{K}$, Moriwakia T, Ninomiyaa $\mathrm{K}$, Ohkawaa T, Umegakia M, Kishimaa $\mathrm{H}$ and Yoshiminea $\mathrm{T}$. (2015): Isolation of human adult olfactory sphere cells as a cell source of neural progenitors. Stem Cell Res; 15:23-29.

22- Derenzis FA and Schechtman A. (1973): Staining by neutral red and trypan blue in sequence for assaying vital and nonvital cultured cells. Stain technol; 48(3):135-136.

23- Katsares V, Petsa A, Felesakis A, Paparidis Z, Nikolaidou E, Gargani $S$ and Grigoriadis J. (2015): A rapid and accurate method for the stem cell viability evaluation: the case of the thawed umbilical cord blood. Lab Med; 40(9):557-560.

24- Valverde F, Heredia $M$ and Santacana M. (1993): Characterization of neuronal cell varieties migrating from the olfactory epithelium during prenatal development in the rat. Immunocytochemical study using antibodies against olfactory marker protein (OMP) and luteinizing hormone-releasing hormone (LHRH). Dev br res; 71:209-220.

25-Sayuri S, Jun N, Shinsuke S, Yumi M, and Hideyuki O. (2010): The neural stem/progenitor cell marker nestin Is expressed in proliferative endothelial cells, but not in mature vasculature. J Histochem Cytochem; 58:721-730.

26-Hosseini SM, Farahmandnia M, Razi Z, Delavari S, Shakibajahromi B, Sarvestani FS, Kazemi S and Semsar M. (2015): Combination cell therapy with mesenchymal stem cells and neural stem cells for brain stroke in rats. Int J Stem Cells; 8:99-105.

27- Kuijten M, Ginn C, Khaw P, Limb GA and Brocchini S. (2014): Identification and characterization of neural crest stem cells in rat olfactory mucosa as a use for cellmediated neuroprotection as treatment of glaucoma. Invest Ophthalmol Vis Sci; 55(13):13591359.

28- Gritti A, Bonfanti L, Doetsch F, Caille I, Alvarez-Buylla A, Lim DA and Vescovi AL. (2002): Multipotent neural stem cells reside into the rostral extension and olfactory bulb of adult rodents. J Neurosci; 22(2):437-445.

29-Curtis MA, Kam M, Nannmark U, Anderson MF, Axell MZ, Wikkelso C and Frisén J. (2007): Human neuroblasts migrate to the olfactory bulb via a lateral ventricular extension. Sci; 315(5816):12431249.

30- Pagano SF, Impagnatiello F, Girelli M, Cova L, Grioni E, Onofri M and Solero CL. (2000): Isolation and characterization of neural stem cells from the adult human olfactory bulb. Stem cells; 18(4):295-300.

31- Ercolin ACM, Roballo KCS, Casals JB, Pieri NCG, Souza AF, Barreto RDSN and Ambrósio CE. (2016): Rabbit olfactory stem cells. 
Isolation protocol and characterization. Acta Cirurgica Brasileira, 31(1):59-66.

32- Vergano Vera E, Diaz Guerra E, Rodríguez Traver E, Mendez Gomez HR, Solis O, Pignatelli, J and Vicario Abejon C. (2015): Nurr1 blocks the mitogenic effect of FGF 2 and EGF, inducing olfactory bulb neural stem cells to adopt dopaminergic and dopaminergic GABAergic neuronal phenotypes. Developmental neurobiol; 75(8):823-841.

33- Basma H, Soto-Gutiérrez A, Yannam GR, Liu L, Ito R, Yamamoto $\mathrm{T}$ and Muirhead $\mathrm{D}$. (2009): Differentiation and transplantation of human embryonic stem cell-derived hepatocytes. Gastroenterol; 136(3):9 90-999.

34- Park IH, Lerou PH, Zhao R, Huo $H$ and Daley GQ. (2008): Generation of human-induced pluripotent stem cells. Nature protocols, 3(7):11801186.

35- Gong XJ, Sun L, Li JY, Yuan L, Liu Q and Chen WP. (2009): Isolation and culture of neural stem cells from Kunming mouse embryo. J Clin Rehabilitative Tissue Eng Res; 13(23):4573-4576.

36- Amoh Y, Li L, Katsuoka K, Penman $S$ and Hoffman RM. (2005): Multipotent nestin-positive, keratin-negative hair-follicle bulge stem cells can form neurons. Proceedings of the National academy of Sciences of the
United States of America; 102(15):5530-5534.

37- Van der Valk J, Brunner D, De Smet K, Svenningsen ÅF, Honegger $\mathrm{P}$, Knudsen LE and Gstraunthaler G. (2010): Optimization of chemically defined cell culture media-replacing fetal bovine serum in mammalian in vitro methods. Toxicol in vitro; 24(4):1053-1063.

38- Jochems CE, Van Der Valk JB, Stafleu FR and Baumans V. (2002): The use of fetal bovine serum: ethical or scientific problem?. ATLA-NOTTINGHAM; 30(2):219-228.

39- Liu Z and Martin LJ. (2003): Olfactory bulb core is a rich source of neural progenitor and stem cells in adult rodent and human. $J$ Compar Neurol; 459(4): 368-391.

40- Ercolin ACM, Roballo, KCS, Casals JB, Pieri NCG, Souza AF, Barreto RDSN and Ambrosio CE. (2016): Rabbit olfactory stem cells. Isolation protocol and characterization. Acta Cirurgica Brasileira; 31(1):59-66.

41- Hematti P. (2012): Mesenchymal stromal cells and fibroblasts: a case of mistaken identity. Cytotherapy; 14 (5):516-521.

42- Girard SD, Deveze A, Nivet E, Gepner B, Roman FS and Feron F. (2011): Isolating nasal olfactory stem cells from rodents or humans. J Vis Exp; 54:2762. 